\title{
Assessment of tidal volume and thoracoabdominal motion using volume and flow-oriented incentive spirometers in healthy subjects
}

V.F. Parreira, G.M. Tomich, R.R. Britto and R.F. Sampaio
Departamento de Fisioterapia, Escola de Educação Física, Fisioterapia e Terapia Ocupacional, Universidade Federal de Minas Gerais, Belo Horizonte, MG, Brasil
Correspondence

V.F. Parreira

Dona Cecília, 500, Apto. 1504

30220-070 Belo Horizonte, MG Brasil

Fax: +55-31-3499-4790

E-mail: parreira@ufmg.br

Research partially supported by CNPq.

Received March 16, 2004 Accepted February 10, 2005

\section{Abstract}

The objective of the present study was to evaluate incentive spirometers using volume- (Coach and Voldyne) and flow-oriented (Triflo II and Respirex) devices. Sixteen healthy subjects, $24 \pm 4$ years, $62 \pm 12$ $\mathrm{kg}$, were studied. Respiratory variables were obtained by respiratory inductive plethysmography, with subjects in a semi-reclined position $\left(45^{\circ}\right)$. Tidal volume, respiratory frequency, minute ventilation, inspiratory duty cycle, mean inspiratory flow, and thoracoabdominal motion were measured. Statistical analysis was performed with Kolmogorov-Smirnov test, $t$-test and ANOVA. Comparison between the Coach and Voldyne devices showed that larger values of tidal volume $(1035 \pm 268 v s 947 \pm 268 \mathrm{ml}, \mathrm{P}=0.02)$ and minute ventilation $(9.07$ \pm 3.61 vs $7.49 \pm 2.581 / \mathrm{min}, \mathrm{P}=0.01$ ) were reached with Voldyne, whereas no significant differences in respiratory frequency were observed $(7.85 \pm 1.24$ vs $8.57 \pm 1.89 \mathrm{bpm})$. Comparison between floworiented devices showed larger values of inspiratory duty cycle and lower mean inspiratory flow with Triflo II $(0.35 \pm 0.05$ vs $0.32 \pm 0.05$ $\mathrm{ml} / \mathrm{s}, \mathrm{P}=0.00$, and $531 \pm 137$ vs $606 \pm 167 \mathrm{ml} / \mathrm{s}, \mathrm{P}=0.00$, respectively). Abdominal motion was larger $(\mathrm{P}<0.05)$ during the use of volumeoriented devices compared to flow-oriented devices $(52 \pm 11 \%$ for Coach and $50 \pm 9 \%$ for Voldyne; $43 \pm 13 \%$ for Triflo II and $44 \pm 14 \%$ for Respirex). We observed that significantly higher tidal volume associated with low respiratory frequency was reached with Voldyne, and that there was a larger abdominal displacement with volumeoriented devices.

\section{Introduction}

Many therapeutic devices used to prevent postoperative pulmonary complications (PPC) have been described (1). PPC are clinically significant alterations in pulmonary function associated with the postoperative
Key words

- Incentive spirometry

- Respiratory inductive plethysmography

- Physiotherapy

- Volume-oriented spirometer

- Flow-oriented spirometer 
compliance, impaired mucociliary clearance, and a monotonous breathing pattern without periodic sighs (2-5).

Many clinical investigations about the mechanism and treatment of PPC have been performed, but there is no therapeutic consensus about them, nor has any method been described as superior (1). However, because of the frequent changes occurring during the postoperative period, especially alterations of the breathing pattern that can cause progressive alveolar collapse, it is known that a crucial factor in the prevention and treatment of PPC is the maintenance of intermittent deep prolonged inspiratory efforts, which can reinflate collapsed alveoli, increase pulmonary compliance and reduce regional ventilation-perfusion inequalities $(6,7)$.

The first incentive spirometer was constructed by Bartlett et al. (8) in the 1970's to encourage through visual feedback the performance of reproducible, sustained maximal inspiration, until total lung capacity. Maximal inspirations cause an increase in transpulmonary pressure and consequently an increase in lung volume $(6,9)$. An endinspiratory pause maintains this increase in transpulmonary pressure and ensures alveolar stability $(6,10,11)$.

Incentive spirometers are instrumental devices commonly used in clinical practice (12) and the literature provides specific guidelines (13) and a rationale for their use (6). Different kinds of devices, volume or floworiented, are currently available (14). Several studies have been conducted to evaluate the efficacy of incentive spirometry (IS) for the prevention and treatment of PPC after thoracic, abdominal or thoracoabdominal surgery, and to compare this technique with other treatment programs. However, the results obtained in these studies have been conflicting (3,4,15-18). Overend et al. (3) concluded that there is no evidence to support the use of IS to decrease the incidence of PPC following thoracic or upper abdominal surgeries. This lack of evidence could be attributed to methodological flaws. At present, IS continues to be used as part of the routine prophylactic and therapeutic regimen for respiratory care (19).

Other aspects considered to analyze the efficacy of IS, such as diaphragmatic recruitment, influence of body position and additional imposed breathing work, have also been studied $(18,20,21)$. Two of these studies showed a higher work of breathing during the use of flow-oriented devices compared to volume-oriented devices $(18,21)$. To date, only few studies about IS have focused on technical aspects such as the difference between required and measured volume or flow levels, and on physiological aspects such as thoracoabdominal motion during the use of different incentive spirometers based on the same functioning principle.

The present study had two main purposes. The first was to evaluate tidal volume and thoracoabdominal motion using volumeand flow-oriented incentive spirometers; the second was to compare the required volume of volume-oriented incentive spirometers with the actual tidal volume, and the estimated inspiratory flow of flow-oriented incentive spirometers with the mean inspiratory flow actually measured. A secondary purpose was to evaluate oxygen saturation and heart rate during the use of these incentive spirometers.

\section{Material and Methods}

\section{Subjects}

Twenty subjects were selected for the study. They were Human and Health Sciences professors or university students who volunteered for the study. Two subjects were excluded because their pulmonary function test presented obstructive or restrictive disorders and two others were unable to perform the test adequately. Thus, 16 non-smoking healthy subjects without a history of 
respiratory disease were studied: 9 women and 7 men aged $24 \pm 4$ years (mean \pm SD), age range: $21-38$ years, weight $62 \pm 12 \mathrm{~kg}$, height $1.68 \pm 0.10 \mathrm{~m}$, body mass index: $21.96 \pm 2.41 \mathrm{~kg} / \mathrm{m}^{2}$. A pulmonary function test was performed with a hand-held spirometer (Vitalograph 2120, Vitalograph Ltd., Buckingham, England). The mean values of the spirometric variables, reported as percent of predicted according to Knudson values (22) were: $\mathrm{FVC}=98.8 \pm 8.6 \%, \mathrm{FEV}_{1}=$ $100.1 \pm 7.4 \%, \mathrm{FEV}_{1} / \mathrm{FVC}=101.6 \pm 6.8 \%$, $\mathrm{PEF}=104 \pm 15.6 \%$, FEF $25-75 \%=94.5 \pm$ $20.8 \%$. Subjects had never seen or used IS before and received instructions about the procedure and how to use the devices just before the measurements. All subjects received the same instructions as follows: inspire deeply and slowly through the mouthpiece of the spirometer, trying to displace the abdomen beyond the rib cage, and expire. Subjects gave written informed consent to participate in the study, which was approved by the University Ethics Research Committee.

\section{Signals and recording equipment}

Respiratory variables were obtained by respiratory inductive plethysmography (Respitrace $^{\circledR}$, Nims, Miami, FL, USA). Tefloncoated inductance coils of appropriate size were placed around the rib cage and abdomen; the upper edge of the rib cage band was placed at the level of the axilla and the abdominal band at the level of umbilicus. Signals were calibrated using qualitative diagnostic calibration (23) during natural breathing; this is a two-step procedure whereby the rib cage and abdominal electrical gains of the respiratory inductive plethysmography amplifiers are correctly partitioned during tidal breathing and subsequently compared to the output of a spirometer to attain equivalence. The subject then breathed into a spirometer via a mouthpiece (Vitatrace, Pro Médico, Rio de Janeiro, RJ, Brazil) with the nose clipped, for 30 to $60 \mathrm{~s}$, and the electrical spirometer output was recorded with a computer and used to calibrate the respiratory inductive plethysmographic sum signal for absolute volume in $\mathrm{ml}$ (24). The spirometer was calibrated with a 3-liter syringe (Hans Rudolph Inc., Kansas City, MO, USA) using computer software (RespiPanel 4.0, Nims) and signals were recorded with a digital acquisition system (RespiEvents 5.2, Nims). Transcutaneous oxygen saturation $\left(\mathrm{SpO}_{2}\right)$ and pulse rate were recorded by pulse oximetry (Datex-Ohmeda Inc., Louisville, $\mathrm{CO}$, USA) using a finger probe.

\section{Procedure}

Subjects lay comfortably in bed in a semireclined position $\left(45^{\circ}\right)$, avoiding any shift of the body during recording. Respitrace ${ }^{\circledR}$ and the finger sensor of the pulse oximeter were then applied. Four incentive spirometers were used: two of them volume-oriented devices (Coach, DHD Medical Products, Canasota, NY, USA, and Voldyne, Hudson RCI, Temecula, CA, USA), with a predetermined volume of $1500 \mathrm{ml}$, and two flow-oriented devices (Triflo II, Hudson RCI, and Respirex, DHD Medical Products), set at a flow rate of $900 \mathrm{ml} / \mathrm{s}$. The choice of these devices was based on the fact that these incentive spirometers are commonly used in our clinical settings. The target of volume-oriented IS was chosen as a function of the tidal volume of approximately $400 \mathrm{ml}$ described in the literature for young adults (25). According to Bendixen et al. (26), sigh volume corresponds to 2 or 3 times the tidal volume. Our choice was based on this consideration $(3 \mathrm{x}$ $400 \mathrm{ml}=1200 \mathrm{ml}$ ). However, for the Coach and Voldyne devices it is easier to visualize $1500 \mathrm{ml}$. For flow-oriented IS, the literature recommends to raise the first two balls of the Triflo II device corresponding to $900 \mathrm{ml} / \mathrm{s}$ $(14,27)$. To have equivalence between floworiented devices we chose the same flow level for the Respirex device. 
After calibration, 5-min baseline periods were recorded and then the test with the first incentive spirometer was performed. The following sequence was used: 1 st baseline period, 1st device, 2nd baseline, 2nd device, 3rd baseline, 3rd device, 4th baseline, 4th device, and the 5th and last baseline period. At least $5 \mathrm{~min}$ of recording was allowed for each baseline period. For each IS period 1 min or at least 8 breaths were recorded. A custom-made random number generator program was used to assign the order in which the incentive spirometers would be used for each subject. Just before and after each IS trial $\mathrm{SpO}_{2}$ and pulse rate were recorded.

\section{Measurements}

For the baseline periods, only tidal volume was analyzed. For each IS period, all individual values for tidal volume $(\mathrm{Vt})$, respiratory frequency (f), minute ventilation, inspiratory duty cycle (Ti/Ttot), mean inspiratory flow $(\mathrm{Vt} / \mathrm{Ti})$, and rib cage motion contribution to $\mathrm{Vt}(\% \mathrm{RC} / \mathrm{Vt})$ were obtained directly via the digital acquisition system, on a breath by breath basis. The abdominal motion contribution to $\mathrm{Vt}$ was calculated breath by breath $(\% \mathrm{AB} / \mathrm{Vt}=100-\% \mathrm{RC} / \mathrm{Vt})$.

\section{Statistical analysis}

Data are reported as means \pm SD. Statistical analysis was performed with the Statistical Package for Social Sciences (SPSS 10.0, Chicago, IL, USA). Distribution analysis was performed using the Kolmogorov-Smirnov test. ANOVA for repeated measures was performed, followed by the Tukey-Kramer post hoc test (Vt for baseline data and $\mathrm{f}, \mathrm{Ti} /$ Ttot, $\% \mathrm{RC} / \mathrm{Vt}$, and $\% \mathrm{AB} / \mathrm{Vt}$ for the IS periods). The data obtained for all respiratory variables with two volume-oriented and two flow-oriented spirometers were compared by independent sample $t$-test. The volume and flow required by the incentive spirometers and those actually measured were com- pared by one-sample $t$-test. Data regarding transcutaneous oxygen saturation $\left(\mathrm{SpO}_{2}\right)$ and pulse rate before and after IS were compared by the Student $t$-test for paired samples. The level of significance $(\alpha)$ was set at 0.05 for all tests.

\section{Results}

Data were obtained during the five baseline and four IS periods for all 16 subjects. Four of them repeated one of the IS periods (two subjects with Triflo II, one with Respirex and one with Coach). A total of 689 respiratory cycles of IS periods were analyzed, with a mean $( \pm \mathrm{SD})$ of $43 \pm 5$ cycles per subject. With respect to the five baseline periods, a total of 1224 respiratory cycles were analyzed, with a mean of $76 \pm 13$ cycles per subject. For baseline data the mean was calculated from 1-min measurements corresponding to the last minute of each baseline period (approximately 15 breaths).

\section{Baseline tidal volume}

The following $\mathrm{Vt}$ values (mean $\pm \mathrm{SD}$ ) were obtained during the five baseline periods: baseline 1 (277 $\pm 106 \mathrm{ml})$, baseline 2 $(296 \pm 145 \mathrm{ml})$, baseline $3(270 \pm 118 \mathrm{ml})$, baseline $4(286 \pm 117 \mathrm{ml})$, and baseline 5 $(274 \pm 94 \mathrm{ml})$. There were no significant differences in tidal volume between the five baseline periods $(\mathrm{F}=0.40 ; \mathrm{P}=0.80)$.

\section{Comparison of Coach and Voldyne (volume-oriented incentive spirometers)}

Table 1 shows the data obtained with volume-oriented incentive spirometers with a required volume of $1500 \mathrm{ml}$. Comparison showed that higher tidal volume and minute ventilation values were reached with Voldyne $(\mathrm{P}<0.05)$. Mean inspiratory flow was lower and inspiratory duty cycle was longer when Coach was used $(\mathrm{P}<0.05)$. With respect to respiratory frequency, rib cage and abdomi- 
nal motion contribution to $\mathrm{Vt}$, there were no significant differences between spirometers.

\section{Comparison of Respirex and Triflo II (flow-oriented incentive spirometers)}

Table 2 shows the data obtained with the flow-oriented incentive spirometers set at $900 \mathrm{ml} / \mathrm{s}$. Comparison showed that higher values of inspiratory duty cycle and lower mean inspiratory flow were reached when Triflo II was used $(\mathrm{P}<0.05)$. No significant differences were observed for tidal volume, respiratory frequency, minute ventilation, rib cage, and abdominal motion contribution to $\mathrm{Vt}$.

\section{Comparison of volume- and flow-oriented incentive spirometers}

Thoracoabdominal motion during incentive spirometry. Figure 1 shows the thoracoabdominal motion data obtained with the use of the four incentive spirometers. Abdominal motion was significantly higher than rib cage motion when volume-oriented incentive spirometers were used compared to flow-oriented devices. No significant difference was observed between Coach and Voldyne (volume-oriented devices) or Respirex and Triflo II (flow-oriented devices) for $\% \mathrm{AB} / \mathrm{Vt}$ or $\% \mathrm{RC} / \mathrm{Vt}$.

Comparison of the volume and flow required by the incentive spirometers and those actually measured. A significant difference was observed for both volume-oriented devices when the tidal volume reached during IS (Table 1) was compared to the required volume of $1500 \mathrm{ml}$ (Coach: $\mathrm{t}=-8.21 ; \mathrm{P}=$ 0.00 and Voldyne: $\mathrm{t}=-6.91 ; \mathrm{P}=0.00)$. Similarly, a significant difference was observed for both flow-oriented devices when the mean inspiratory flow reached during IS (Table 2) was compared to the estimated flow of $900 \mathrm{ml} / \mathrm{s}$ for the incentive spirometers (Respirex: $\mathrm{t}=-6.99 ; \mathrm{P}=0.00$; Triflo II: $\mathrm{t}=-10.71 ; \mathrm{P}=0.00)$.
Table 1. Data obtained with volume-oriented incentive spirometers for healthy subjects.

\begin{tabular}{lcc}
\hline $\begin{array}{l}\text { Respiratory } \\
\text { variables }\end{array}$ & Coach & Voldyne \\
\hline $\mathrm{Vt}(\mathrm{ml})$ & $947.94 \pm 268.66$ & $1035.88 \pm 268.43^{*}$ \\
$\mathrm{f}(\mathrm{bpm})$ & $7.85 \pm 1.24$ & $8.57 \pm 1.89$ \\
$\mathrm{VE}(\mathrm{I} / \mathrm{min})$ & $7.49 \pm 2.58$ & $9.07 \pm 3.61^{*}$ \\
$\mathrm{Ti} / \mathrm{Ttot}$ & $0.55 \pm 0.06$ & $0.48 \pm 0.08^{*}$ \\
$\mathrm{Vt} / \mathrm{Ti}(\mathrm{ml} / \mathrm{s})$ & $233.80 \pm 98.08$ & $338.31 \pm 199.96^{*}$ \\
$\% \mathrm{RC} / \mathrm{Nt}$ & $47.41 \pm 10.99$ & $49.11 \pm 8.94$ \\
$\% \mathrm{AB} / \mathrm{Nt}$ & $52.58 \pm 10.99$ & $50.88 \pm 8.94$ \\
\hline
\end{tabular}

Data are reported as means \pm SD for 16 subjects. $\mathrm{Vt}=$ tidal volume; $\mathrm{f}=$ respiratory frequency; $\mathrm{VE}=$ minute ventilation; $\mathrm{Ti} / \mathrm{T}$ tot $=$ inspiratory duty cycle; $\mathrm{Vt} / \mathrm{Ti}=$ mean inspiratory flow; \% RCN $\mathrm{t}=$ rib cage motion contribution to $\mathrm{Vt}$; $\% \mathrm{ABNt}=$ abdominal motion contribution to $\mathrm{Vt}$.

${ }^{*} \mathrm{P}<0.05$ compared to Coach device (Student $t$ test).

Table 2. Data obtained with flow-oriented incentive spirometers for healthy subjects.

\begin{tabular}{lcc}
\hline $\begin{array}{l}\text { Respiratory } \\
\text { variables }\end{array}$ & Respirex & Triflo II \\
\hline $\mathrm{Vt}(\mathrm{ml})$ & $973.44 \pm 354.54$ & $970.88 \pm 303.94$ \\
$\mathrm{f}(\mathrm{bpm})$ & $12.51 \pm 3.05$ & $12.59 \pm 3.08$ \\
$\mathrm{VE}(\mathrm{I} / \mathrm{min})$ & $11.62 \pm 3.57$ & $11.38 \pm 3.50$ \\
$\mathrm{Ti} / \mathrm{Ttot}$ & $0.32 \pm 0.05$ & $0.35 \pm 0.05^{*}$ \\
$\mathrm{Vt} / \mathrm{Ti}(\mathrm{ml} / \mathrm{s})$ & $606.80 \pm 167.70$ & $531.48 \pm 137.61^{*}$ \\
$\% \mathrm{RC} / \mathrm{Nt}$ & $55.13 \pm 14.10$ & $56.17 \pm 13.44$ \\
$\% \mathrm{AB} / \mathrm{Nt}$ & $44.86 \pm 14.10$ & $43.82 \pm 13.44$
\end{tabular}

Data are reported as means \pm SD for 16 subjects. $\mathrm{Vt}=$ tidal volume; $\mathrm{f}=$ respiratory frequency; $\mathrm{VE}=$ minute ventilation; $\mathrm{Ti} / \mathrm{Ttot}=$ inspiratory duty cycle; $\mathrm{Vt} / \mathrm{Ti}=$ mean inspiratory flow; \% RCN $\mathrm{t}=$ rib cage motion contribution to $\mathrm{Vt}$; \% $\mathrm{ABNt}=$ abdominal motion contribution to $\mathrm{Vt}$

${ }^{*} \mathrm{P}<0.05$ compared to Respirex device (Student $t$ test).

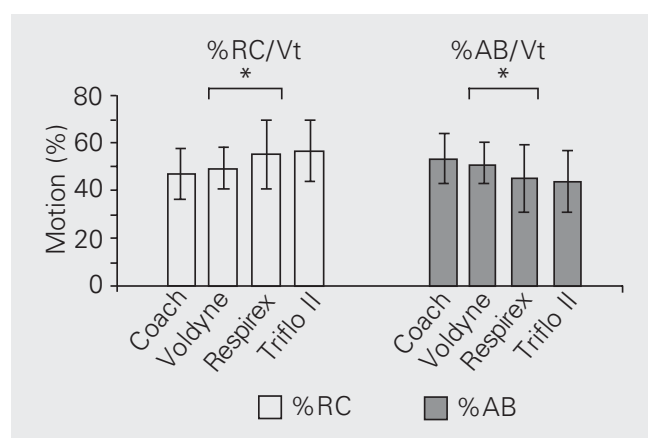

Figure 1. Contribution of rib cage motion to tidal volume (\% RCN $)$ and contribution of abdominal motion to tidal volume (\%AB/ $\mathrm{Vt}$ ). Data of thoracoabdominal motion for the group of 16 subjects using four incentive spirometers, two of them volumeoriented (Coach and Voldyne) and two flow-oriented devices (Respirex and Triflo II). *P $<0.05$ (ANOVA). 
Table 3. Transcutaneous oxygen saturation $\left(\mathrm{SpO}_{2}\right)$ and pulse rate before and after incentive spirometry for healthy subjects.

\begin{tabular}{lll}
\hline $\begin{array}{l}\text { Incentive } \\
\text { spirometer }\end{array}$ & $\begin{array}{c}\text { Before } \\
\text { the trial }\end{array}$ & $\begin{array}{c}\text { After } \\
\text { the trial }\end{array}$ \\
\hline $\begin{array}{l}\mathrm{SpO}_{2}(\%) \\
\text { Coach }\end{array}$ & $95.56 \pm 1.03$ & $97.25 \pm 1.29^{*}$ \\
$\quad$ Voldyne & $96.06 \pm 1.06$ & $97.19 \pm 1.56^{*}$ \\
Respirex & $96.44 \pm 1.15$ & $96.88 \pm 1.20$ \\
$\quad$ Triflo II & $96.19 \pm 1.33$ & $97.19 \pm 1.42^{*}$ \\
Pulse rate (bpm) & & \\
Coach & $72.63 \pm 10.26$ & $72.13 \pm 9.09$ \\
$\quad$ Voldyne & $72.13 \pm 7.64$ & $77.19 \pm 9.55$ \\
$\quad$ Respirex & $72.56 \pm 9.04$ & $72.19 \pm 9.99$ \\
$\quad$ Triflo II & $74.88 \pm 10.33$ & $73.56 \pm 11.55$ \\
\end{tabular}

Data are reported as means \pm SD for 16 subjects. ${ }^{*} \mathrm{P}<0.05$ compared to before trial (Student $t$-test).

\section{Transcutaneous oxygen saturation and pulse rate data}

Table 3 shows the $\mathrm{SpO}_{2}$ and pulse rate data obtained by pulse oximetry. There was a significant difference in $\mathrm{SpO}_{2}$ measured before and after each period of incentive spirometry with all incentive spirometers $(\mathrm{P}$ $<0.05$ ), except for Respirex. No significant differences in pulse rate were observed before and after each period of incentive spirometry with the four incentive spirometers.

\section{Discussion}

The main results of the present study were: 1) when the two volume-oriented incentive spirometers were compared, minute ventilation effectively reaching the lungs was larger with Voldyne due to a larger tidal volume associated with a low respiratory frequency; 2) abdominal motion was larger during the use of volume-oriented incentive spirometers compared to flow-oriented devices; 3 ) in all devices, the actually measured volume for volume-oriented incentive spirometers and mean inspiratory flow for flow-oriented devices differed significantly from those indicated by the manufacturers of incentive spirometers.

The cumulative effects of incentive spirometers did not influence these results because the order of use was randomized and the tidal volume did not show significant differences during baseline measurements.

Since the aim of incentive spirometry is to increase transpulmonary pressure through slow deep maximal inspiration, increasing tidal volume and decreasing respiratory frequency $(6,13)$, the best values of minute ventilation, tidal volume and respiratory frequency were obtained during exercise with volume-oriented incentive spirometers. Minute ventilation was larger during the use of Voldyne due to a larger tidal volume associated with a low respiratory frequency.

Rib cage and abdominal motion contributions to Vt were similar for the two volume-oriented devices and for the two floworiented devices, but not when volume and flow-oriented devices were compared. A larger abdominal motion contribution to $\mathrm{Vt}$ occurred during IS with volume-oriented devices, which could be considered to be an advantage of these devices, since a larger abdominal displacement is desired during IS.

We postulate that the difference observed between volume and flow-oriented incentive spirometers with respect to chest and abdominal motion may be related to breathing work. It was observed that the recruitment pattern of respiratory muscles preferentially occurs with rib cage muscles during incentive spirometry using a flow-oriented device (28) and a higher breathing work is observed during the use of this type of device $(18,21)$. Weindler and Kiefer (18) evaluated the additional imposed work of breathing generated by two different incentive spirometers (Coach, volume-oriented, and Mediflo, flow-oriented) on the postoperative IS performance of patients. For the group with a moderate risk for PPC the additional breathing work imposed by the flow-oriented device was twice the one imposed by 
the volume-oriented device. Mang and Obermayer (21), using a test lung model, tested six different models of incentive spirometers (Coach, Voldyne and Triflo II between them) and observed that Triflo II imposed the highest breathing work. This finding is similar to that obtained in the present study, which demonstrated a higher rib cage motion with Triflo II and Respirex (flow-oriented devices).

In the devices evaluated by us, the actually measured volume for volume-oriented incentive spirometers and flow for floworiented devices differed significantly from those indicated by the manufacturers (about $40 \%$ ). The tidal volume measured differed significantly between the volume-oriented devices even though the subjects reached the same levels on the cylinders. This fact might be related to leak or friction on the cylinder. This difference was also reported by Mang et al. (29) in a study about incentive spirometers. The largest difference was observed with flow-oriented devices $(25-50 \%$ above the flow declared by the manufacturers) but a difference was also observed with volumeoriented devices $( \pm 10 \%)$. These results observed by us and others show that there is a source of error when this therapy is used and could help to explain inconsistent results published in the literature evaluating the efficacy of IS. This matter deserves further investigation.

In our study, we analyzed the use of IS by subjects without previous knowledge of the technique, a fact that can influence the performance obtained during the measurements. However, our purpose with this inclusion criterion was to simulate the clinical context, in which the patients are not necessarily familiar with IS.
Our results showed that $\mathrm{SpO}_{2}$ was significantly increased after IS in all but one IS device. With healthy subjects these $\mathrm{SpO}_{2}$ values were not clinically significant despite being statistically different. Monitoring of $\mathrm{SpO}_{2}$ during the use of IS should be recommended when working with patients at risk for PPC.

Limitations of the present study can be the fact that we studied healthy subjects and that a relation between this experimental situation and clinical situations involving patients cannot be directly established. However, studies on the influence of body position during incentive spirometry in normal subjects and patients submitted to surgery obtained similar results $(20,30)$.

Another limitation could be a possible influence of different settings of volume and flow devices on results related to thoracoabdominal motion. Although this was not an aim in this study, we observed close tidal volume measured using volume- or floworiented incentive spirometers. In view of these considerations, we believe that the differences observed in thoracoabdominal motion between volume and flow IS were not related to targets but to the characteristics of each device.

Our results showed that a larger tidal volume associated with a low respiratory frequency, resulting in higher minute ventilation, was reached when subjects used Voldyne, a volume-oriented incentive spirometer. Abdominal motion during the use of incentive spirometers was higher with volume-oriented devices. In all devices, the actually measured volume or flow differed significantly from those indicated by the manufacturers. 


\section{References}

1. Scuderi J \& Olsen GN (1989). Respiratory therapy in the management of postoperative complications. Respiratory Care, 34: 281291.

2. Craig DB (1981). Postoperative recovery of pulmonary function. Anesthesia and Analgesia, 60: 46-52.

3. Overend TJ, Anderson CM, Lucy SD, Bhatia C, Jonsson BI \& Timmermans C (2001). The effect of incentive spirometry on postoperative pulmonary complications. Chest, 120: 971-978.

4. Rezaiguia S \& Jayr C (1996). Prévention des complications respiratoires après chirurgie abdominale. Annales Françaises d'Anesthésie et de Réanimation, 15: 623-646.

5. Marini JJ (1984). Postoperative atelectasis: pathophysiology, clinical importance, and principles of management. Respiratory Care, 29: 516-522.

6. Bakow ED (1977). Sustained maximal inspiration - a rationale for its use. Respiratory Care, 22: 379-382.

7. Douce FH (1994). Incentive spirometry and other aids to lung inflation. In: Barnes G (Editor), Core Text Book. McGraw Hill, New York.

8. Bartlett RH, Gazzaniga AB \& Geraghty TR (1973). Respiratory maneuvers to prevent postoperative pulmonary complications. A critical review. Journal of the American Medical Association, 224: 10171021.

9. Williams JV, Tierney DF \& Parker HR (1966). Surface forces in the lung, atelectasis, and transpulmonary pressure. Journal of Applied Physiology, 21: 819-827.

10. Ward RJ, Danziger F, Bonica JJ, Allen GD \& Bowes J (1966). An evaluation of postoperative respiratory maneuvers. Surgery, Gynecology and Obstetrics, 7: 51-54.

11. Knelson JH, Howatt WF \& DeMuth GR (1970). Effect of respiratory pattern on alveolar gas exchange. Journal of Applied Physiology, 29: 328-331.

12. O'Donohue WJJ (1985). National survey of the usage of lung expansion modalities for the prevention and treatment of postoperative atelectasis following abdominal and thoracic surgery. Chest, 87: 7680

13. American Association for Respiratory Care (1991). Clinical Practice Guidelines - Incentive Spirometry. Respiratory Care, 36: 1402-1405.

14. Wojciechowski WV (1994). Incentive spirometers, secretion evacuation devices, and inspiratory muscle training devices. In: Barnes G (Editor), Core Text Book. McGraw Hill, New York.

15. Chuter TAM, Weisman C, Starker P \& Gump FE (1989). Effect of incentive spirometry on diaphragmatic function after surgery. Surgery, 105: 488-493.

16. Thomas JA \& Mclntosh JM (1994). Are incentive spirometry, intermittent positive pressure breathing and deep breathing exercises effective in the prevention of postoperative pulmonary complications after upper abdominal surgery? A systematic overview and meta-analysis. Physical Therapy, 74: 3-10.
17. Gosselink R, Schrever K, Cops P, Witvrouwen H, De Leyn $P$, Trooters T, Lerut A \& Denneffe G (2000). Incentive spirometry does not enhance recovery after thoracic surgery. Critical Care Medicine, 28: 679-683.

18. Weindler J \& Kiefer T (2001). The efficacy of postoperative incentive spirometry is influenced by the device-specific imposed work of breathing. Chest, 119: 1858-1864.

19. Wattie J (1998). Incentive spirometry following coronary artery bypass surgery. Physiotherapy Canada, 84: 508-514.

20. Melendez JA, Alagesan R, Reinsel R, Weisman C \& Burt M (1992). Postthoracotomy respiratory muscle mechanics during incentive spirometry using respiratory inductance plethysmography. Chest, 101: $432-436$

21. Mang $\mathrm{H}$ \& Obermayer $A$ (1989). Imposed work of breathing during sustained maximal inspiration: comparison of six incentive spirometers. Respiratory Care, 34: 1122-1128.

22. Knudson RJ, Lebowitz MD, Holberg CJ \& Burrows B (1983). Changes in the normal maximal expiratory flow-volume curve with growth and aging. American Review of Respiratory Disease, 127: 725-734.

23. Sackner MA, Watson $H$, Belsito A, Feinerman D, Suarez $M$ \& Gonzalez G (1989). Calibration of respiratory inductive plethysmography during natural breathing. Journal of Applied Physiology, 66: 410-420.

24. Bloch KE, Barandun J \& Sackner MA (1995). Effect of mouthpiece breathing on cardiorespiratory response to intensive exercise. American Journal of Respiratory and Critical Care Medicine, 151: 1087-1092.

25. Tobin MJ, Chadha TS, Jenouri GB, Birch SJ, Gazeroglu HB \& Sackner MA (1983). Breathing patterns: normal subjects. Chest, 84 : 202-205.

26. Bendixen HH, Smith GM \& Mead J (1964). Pattern of ventilation in young adults. Journal of Applied Physiology, 19: 195-198.

27. Branson RD, Hess DR \& Chatburn RL (1995). Devices for chest physiotherapy, incentive spirometry, and intermittent positive-pressure breathing. In: Branson RD (Editor), Respiratory Care Equipment. JB Lippincott, Philadelphia, PA, USA.

28. Bolina IC, Coelho RMR, Torres MMC, Andrade AFD \& RodriguesMachado MG (2002). Effect of flow and volume-oriented incentive spirometry on diaphragmatic and scalenus muscles activation. European Respiratory Journal, 20 (Suppl 38): 180s (Abstract).

29. Mang $H$, Weindler J \& Zapf $L$ (1989). Postoperative respiratory therapy using incentive spirometry. Anaesthesist, 38: 200-205.

30. Parreira VF, Coelho EM, Tomich GM, Alvim A, Sampaio RF \& Britto RR (2004). Avaliação do volume corrente e da configuração toracoabdominal durante o uso de espirômetros de incentivo a volume e a fluxo, em sujeitos saudáveis: influência da posição corporal. Revista Brasileira de Fisioterapia, 8: 45-51. 